\title{
Influence of supplementary cementitious materials on water transport kinetics and mechanical properties of hydrated lime and cement mortars
}

\author{
C. Ince ${ }^{\mathrm{a}} \bowtie$, S. Derogar ${ }^{\mathrm{a}}$, T.M. Michelitsch ${ }^{\mathrm{b}}$ \\ a. Yeditepe University (Istanbul, Turkey) \\ b. Université Pierre et Marie Curie, (Paris, France) \\ $\triangle$ ceren.ince@yeditepe.edu.tr
}

Received 4 August 2014

Accepted 17 December 2014

Available on line 13 M ay 2015

\begin{abstract}
The purpose of this paper is an investigation of the possible role of supplementary cementitious materials (SCMs) on water transport kinetics and mechanical properties of hydrated lime (CL90) and Portland cement (PC) mortars. The properties of hydrated lime are significantly different from those of cement and therefore modifying fresh and hardened properties of these mortars are vital for mortar/substrate optimisation in masonry construction. The parameters investigated in this paper often are the main barriers to the use of hydrated lime in construction practice. The results show that transfer sorptivity and time to dewater freshly-mixed hydrated lime mortars can be modified when binder is partially replaced with SCMs. Compressive strength of CL90 mortars is increased systematically with the increased replacement levels of SCMs and the results are supported with the microstructural images. The ability to modify the water transport kinetics and mechanical properties allows compatibility between the mortar and the substrate unit in masonry construction.
\end{abstract}

KEYWORDS: Mortar; Lime; Transport properties; Scanning electron microscopy (SEM)

Citation/Citar como: Ince, C.; Derogar, S.; Michelitsch, T.M. (2015) Influence of supplementary cementitious materials on water transport kinetics and mechanical properties of hydrated lime and cement mortars. Mater. Construcc. 65 [318], e056 http://dx.doi.org/10.3989/mc.2015.05214.

RESUMEN: Influencia de los materiales cementantes suplementarios sobre la cinética de transporte de agua y las propiedades mecánicas de cal hidratada y morteros de cemento. El objetivo de este artículo es investigar el papel de los materiales cementantes suplementarios (SCMs) en la cinética de transporte del agua y en las propiedades mecánicas de los morteros de cal hidratada (CL90) y cemento Portland. Las propiedades de la cal hidratada son significativamente diferentes a las del cemento y por lo tanto el control de las propiedades de los morteros frescos y endurecidos es fundamental en la optimización mortero/substrato en albañilería. Los parámetros estudiados en este trabajo son a menudo las principales barreras para el uso de la cal hidratada en la práctica de la construcción. Los resultados indican que la absortividad y el tiempo necesario para deshidratar morteros de cal hidratada recién mezclados pueden ser controlados cuando el conglomerante es parcialmente remplazado por SCMs. La resistencia a compresión de los morteros CL90 aumenta sistemáticamente con el nivel de sustitución de SCM. Las imágenes microestructurales realizadas, confirman estos resultados. La posibilidad de manipular la cinética de transporte de agua y las propiedades mecánicas permite la compatibilidad entre el mortero y la unidad de sustrato en albañilería.

PALABRAS CLAVE: Mortero; Cal; Propiedades de transporte; Microscopía electrónica de barrido (MEB)

Copyright: (C) 2015 CSIC. This is an open-access article distributed under the terms of the Creative Commons Attribution-Non Commercial (by-nc) Spain 3.0 License. 


\section{LIST OF NOTATION}

$A \quad$ is the transfer sorptivity

$R \quad$ is the desorptivity

$S \quad$ is the soptivity

$L \quad$ is the thickness of the mortar bed

$t_{\mathrm{dw}}$ is the time to dewater

$\alpha$ is the parameter that involves both initial and final volume fraction of water and solids content

$\theta_{\mathrm{i}} \quad$ is the volume fraction of water content before dewatering

$\phi_{\mathrm{i}} \quad$ is the volume fraction of water content after dewatering

$\theta_{c}$ is the volume fraction of solids content before dewatering

$\phi_{c}$ is the volume fraction of solids content after dewatering

$\theta \quad$ is the volume fraction of water content

$\phi \quad$ is the volume fraction of solids content

\section{INTRODUCTION}

In masonry construction, mortars, renders and plasters are applied in the freshly-mixed wet state as thin layers to absorbent substrates such as brick, stone and concrete block and they are dewatered by varying amounts by these substrates prior to setting. In practice, the extent to which a freshly mixed mortar is dewatered depends not only on its water retaining characteristics but also on the suction of the substrate to which it is applied, either in the form of render or of jointing mortar in masonry. Dewatering begins immediately when freshly-mixed mortars are placed on top of absorbent substrates. As a consequence of this interaction, fresh and hardened properties of mortars as well as the overall masonry performance are affected significantly. Dewatering of mortar not only affects the strength of the hardened mortar, but also the adhesion of the mortar to the substrate material (1). When freshly mixed wet mortar comes into contact with a dry masonry unit, the water from the fresh mortar is absorbed by the capillary forces of the substrate. In the case of a low suction substrate (e.g. low sorptivity brick) in contact with a high water retaining mortar, poor bond develops between the mortar and the brick as a result of a lack of immediate suction on placing. Conversely, a high suction brick or a very water releasing wet mix also causes an excessive amount of mix water to be withdrawn from the mortar. This does not only result in insufficient water for complete cement hydration but also poor adhesion between brick and mortar. It must also be noted that rapid loss of excessive amount of water within the mortar matrix and hence rapid drying also cause the developments of superficial cracks and fissures on the surface of the mortar. For the practically important case of jointing mortars applied in
$10 \mathrm{~mm}$ layers to a typical facing brick, $40-60 \%$ of the original mix water is lost (2). It was also previously reported in (3) that the loss of mix water during dewatering of freshly mixed mortars when in contact with a dry absorbent substrate results in an increase in strength compared to non-dewatered mortars. It is well known that porosity plays a significant role in determining the mechanical properties of hardened mortars. It was also reported in (3) that the increase in the hydraulicity of the binders results in a decrease in porosity that contributes in the development of mortar strength.

Portland cement (PC) and hydrated lime (CL90) binders are specifically chosen for this study due to their opposing features both at fresh and hardened states. The strong water retaining ability of CL90 mortars and the underlying causes of this behaviour are reported in (4). Besides very differing water retaining characteristics of hydrated lime and cement mortars, compressive strength and setting time are the other major opposing properties of such mortars. We suggest that modifying the fresh and hardened properties would enable more compatible application of these mortars in masonry construction.

The effects of pozzolanic additives on the mechanical properties of air lime mortars are widely reported in the literature. Recently, the influence of clay minerals, metakaolin and brick dust, as pozzolanic additives, on the mechanical properties of lime mortars is investigated by (5-7), while the effects of zeolite, ceramic wastes and the use of perlite on the reactivity and mechanical properties of lime mortars are reported in (8-10) respectively. Large number of studies reported in the literature mainly concerns the use supplementary cementitious materials (SCMs) as a replacement material to cement for improved mechanical properties and durability of concrete (11). Although SCMs are widely used in the concrete industry, their application in mortars in masonry construction is not extensively addressed. The aim of this paper therefore is to investigate the possible role of supplementary cementitious materials on water transport kinetics and mechanical properties of hydrated lime and cement mortars. The parameters investigated are transfer sorptivity $(A)$, time to dewater $\left(t_{\mathrm{dw}}\right)$, consistency, setting time, compressive and flexural strength. The ability to modify these properties using SCMs can therefore lead to the possibility of wet mortar/substrate optimisation and consequently improved properties of the set material.

\section{THEORETICAL BACKGROUND}

The main concern of this paper is the jointing mortars, typically applied to brick, block and stone masonry units. It has conclusively been shown that the rate of dewatering of a wet mix depends on both 
the suction of the absorbent substrate (the sorptivity, $S$ ) and the water retentivity of the fresh mix (the desorptivity, $R)(2,3,12)$. The desorptivity, $R$, defines the water retaining ability of a wet mix which means that lower the value of $R$, the more water retaining the mix. The sorptivity, $S$, defines the ability of a porous material to absorb water by capillarity. The transfer sorptivity, $A$, is a function of both $R$ and $S$ and characterises the ability of a porous material to absorb water from a wet mix (12). These parameters are related by $(12,13)$ :

$$
\frac{1}{A^{2}}=\frac{1}{R^{2}}+\frac{1}{S^{2}}
$$

Equation [1] a full derivation of which may be found in (13), has recently been validated experimentally for the case of clay brick withdrawing water from freshly mixed hydraulic lime and cement mortars (2). Furthermore, an equation based on the Sharp Front theory, describing the time taken to dewater $\left(t_{\mathrm{dw}}\right)$ a wet mix by an absorbent substrate is derived [2]:

$$
t_{d w}=\left(\frac{L \alpha}{A}\right)^{2}
$$

where $L$ is the thickness of the mortar bed, $A$ is the transfer sorptivity and $\alpha$ is the parameter that involves both initial and final volume fraction of water and solids contents. Equation [2] shows that $t_{\mathrm{dw}}$ increases as the thickness of the mortar bed $L$ increases, and decreases as the transfer sorptivity $A$ increases. Time to dewatering also depends on $\alpha$ and definition of $\alpha$ is given in Equation [3]:

$$
\alpha=\theta_{i}-\phi_{i} \frac{\theta_{c}}{\phi_{c}}
$$

$\theta_{\mathrm{i}}, \theta_{\mathrm{c}}$ and $\phi_{\mathrm{i}}, \phi_{\mathrm{c}}$ are the volume fraction of water and solids that are in the mix before and after dewatering respectively and are described by the reduced variable $\alpha$. Initial and final volume fraction of water and solid content are equal to $1(\theta+\phi=1)$. As will be shown later, the parameter $\alpha$ is central to the theoretical predictions of $t_{\mathrm{dw}}$ and is comprehensively discussed in experimental results.

\section{EXPERIMENTAL WORK}

\subsection{Materials}

Experiments were carried out on mortars using hydrated lime (CL90) and Portland cement CEM1 (PC) as binders. The constituents of the mortars examined were the binders (CL90, PC and/or SCMs), fine aggregate (sand) and water. Portland cement and hydrated lime were obtained from Entegre Ltd and comply with (14). The designation CL90 indicates high calcium lime containing not $<90 \%$ $\mathrm{CaO}$. In the case of SCM additions, varying volume fraction replacement levels of fly ash (FA), ground granulated blast furnace slag (GGBS) and silica fume (SF) were used. The FA, was produced by Akcim Mining and Cement Industry Ltd and complies with (15). The FA used in this study conforms to the special fineness (S) category of (15). The GGBS used in the experimental work, manufactured by Cimkul Ltd, complies with (16). The SF, was obtained from Metal Tube Manufacturing Industry Ltd and complies with (17). The fine aggregate used in the study was normal construction sand complying with (18). All the mortars were prepared using a water: binder: sand ratio of $0.75: 1: 2$ by volume as recommended by Entegre Ltd. The mass of binders, SCMs and sand required to produce the desired mix proportions by volume were calculated from carefully determined values of density. CL90 mortar with $50 \%$ FA is prepared using a water: binder: FA: sand ratio of 0.75:0.5:0.5:2, CL90 mortar with 70\% GGBS is prepared using a water: binder: GGBS: sand ratio of $0.75: 0.3: 0.7: 2$ and cement mortar with $50 \% \mathrm{SF}$ is prepared using a water: binder: SF: sand ratio of 0.75:0.5:0.5:2 by volume.

The particle size range, specific surface area, relative particle density and loss on ignition of GGBS, FA, SF, PC, and CL90 are given in Table 1. The oxide and phase compositions derived from XRF analysis are also provided in Table 2. Based on the physical properties of SCMs (Table 1) and the particle size distributions (Figure 3) as well as the oxide and phase compositions derived from XRF analysis of hydrated lime and cement binders (Table 2), it is determined to use the partial replacement levels of GGBS and FA in CL90 mortars and SF in cement mortars to be able to modify the fresh and hardened state properties of these mortars for mortar/substrate optimisation in masonry construction.

The mortar mixing regime described in (19) was followed. The required volume of water was placed into the bowl of an orbital paddle mixer and the binder material added and mixed for 1 minute. Mixing continually, sand was then added over the following one minute and the resultant mortar mixed for a further minute. Mixing was then stopped and all unmixed solids removed from the paddle and the sides of the bowl and incorporated into the mortar. Mixing was then continued giving a total mixing time of 10 minutes. Lime mortars were cured under laboratory conditions (approximately $25^{\circ} \mathrm{C}$ and $50 \% \mathrm{RH}$ ) for 7 days. The samples were then removed from the mold and placed in an environmental chamber to maintain $65 \% \mathrm{RH}$ and $20{ }^{\circ} \mathrm{C}$ for 91 days. All cement mortars were cured under water for 91 days following removal from the mold. 
TABLE 1. The physical properties of PC, CL90, GGBS, FA and SF from the manufacturer's data

\begin{tabular}{lccccc}
\hline Addition & GGBS & FA & SF & PC & CL90 \\
\hline Particle size range $($ microns, $\mu \mathrm{m})$ & $3-100$ & $0.5-120$ & $0.03-0.3$ & $0.2-120$ & $0.5-30$ \\
Specific surface area $\left(\mathrm{m}^{2} / \mathrm{kg}\right)$ & $450-550$ & N/A & 20000 & 405 & 15500 \\
Relative particle density & $2.75-3.00$ & $1.80-2.40$ & $2.20-2.30$ & 3.08 & N/A \\
Loss on ignition & N/A & 5.2 & $<4.00$ & 3.03 & N/A \\
\hline
\end{tabular}

\subsection{Measurement of transfer sorptivity}

The substrate material used in the experimental work was a pressed clay facing brick produced by Ekos Ltd. Prior to transfer sorptivity experiments; the sections were dried to constant weight at $105^{\circ} \mathrm{C}$ in an air oven and the area of the bed face of each section was recorded. Transfer sorptivity is a measure of the ability of an absorbent substrate to withdraw water from a wet mortar mix. Freshly mixed mortar was placed to a depth of $20 \mathrm{~mm}$ into each of five equally sized rectangular compartments in the purpose-built mould. One brick slice was then placed in contact with the mortar in each compartment. To achieve, as nearly as possible, unidirectional absorption the mould was constructed so that the cross sectional area of each compartment was only slightly larger than the brick slices that were used. The brick slices were removed from the mortar consecutively at increasing time intervals and weighed after any adhering mortar had been removed with a stiff brush. The mass, and hence the volume, of water

TABLE 2. Chemical compositions ( $\left.w t^{\%} \%\right)$ of hydrated lime and cement mortars

\begin{tabular}{lrr}
\hline Chemical composition (\% w/w) & CL90 & PC \\
\hline $\mathrm{SiO}_{2}$ & 0.9 & 21.44 \\
$\mathrm{Al}_{2} \mathrm{O}_{3}$ & 0.1 & 5.36 \\
$\mathrm{Fe}_{2} \mathrm{O}_{3}$ & 0.1 & 3.38 \\
$\mathrm{CaO}$ & 72.46 & 60.48 \\
$\mathrm{MgO}$ & 0.7 & 1.05 \\
$\mathrm{~K}_{2} \mathrm{O}$ & 0.02 & 0.65 \\
$\mathrm{Na}_{2} \mathrm{O}$ & 0 & 0.19 \\
$\mathrm{SO}_{3}$ & 0 & 3.47 \\
$\mathrm{Cl}$ & 0 & 0.024 \\
$\mathrm{Loss}$ on ignition & 25.71 & 3.03 \\
$\mathrm{Total}$ & 100 & 99.07 \\
$\mathrm{C}_{2} \mathrm{~S}$ & 0 & 18.5 \\
$\mathrm{Ca}(\mathrm{OH})_{2}$ & 97.1 & - \\
$\mathrm{C}_{3} \mathrm{~S}$ & 0 & 64.7 \\
$\mathrm{C}_{4} \mathrm{AF}$ & 0 & 8.3 \\
$\mathrm{C}_{3} \mathrm{~A}$ & 0 & 7.6 \\
$\mathrm{Total}$ & 97.1 & 99.1 \\
\hline
\end{tabular}

absorbed at five time intervals was thus obtained. The transfer sorptivity was determined from the gradient of the graph of the cumulative absorbed volume of water per unit area of absorbing surface $i$ versus $t^{1 / 2}$. The experiment was designed, from prior knowledge of the relevant parameters, so that both the transfer sorptivity and the initial and final volume fractions of water contents of the wet mix could be obtained prior to setting.

\subsection{Calculation of time to dewater}

\subsubsection{Measurement of the initial volume fraction water and solids content}

The initial volume fraction water content of the wet mix is defined by [4]:

$$
\theta_{\mathrm{i}}=\frac{\text { Volume of water added to mix }}{\text { Volume of wet mix }}
$$

The mass (and hence the volume) of water contained in the wet mix was known precisely, as was the total mass of wet mix produced. In order to determine the total volume of the wet mix, the following procedure was adopted. A small quantity $\left(75 \mathrm{~cm}^{3}\right)$ was removed from the mix and placed into a graduated cylinder. The mass of this known volume was measured in order to calculate the density of the mix. Using this value of density, and the measured total mass of the wet mix, total volume of the wet mix could be calculated. Volume fraction of solids before dewatering, $\phi_{\mathrm{i}}$, is simply calculated as $\theta+\phi=1$.

\subsubsection{Calculation of final volume fraction water and solids content}

The volume fraction water content of the dewatered mix is defined by [5]:

$$
\theta_{c}=\frac{\text { Volume of water remaining in mix }}{\text { Volume of dewatered mix }}
$$

For any compartment in the mould, the initial volume of mortar was known. Since $\theta_{\mathrm{i}}$ was known, the initial volume of water contained in any compartment could be calculated. When the mortar in that compartment had been dewatered, the mass 
(and hence the volume) of water absorbed by the corresponding brick section was measured. The volume of water remaining in the mix was then determined by subtracting the volume of water in the brick section from the initial volume of water in the mix contained in that compartment. Following dewatering, the mass of mortar in the compartment was established by subtracting the mass of water abstracted (i.e. that contained in the brick slice) from the mass of the original mix. The volume of the dewatered mix was determined by density measurement as described previously. From these measurements, the volume fraction of water in the dewatered mix could be established. Volume fraction of solids following dewatering, $\phi_{c}$, is then obtained as $\theta+\phi=1$.

\subsection{Measurement of consistency}

The consistency of the freshly mixed mortars is measured using a flow table. Wet mortar is placed into a standard brass mould at the centre of the flow table top. Mould is filled in two layers following tamping each layer 20 times with a tamper. The excess mortar is removed from the top of the mould using the palette knife and the area around the base of the mould cleaned prior to the experiment. A period of approximately 15 seconds is allowed to elapse and the mould is then removed gradually. The table is jolted 15 times at a rate of approximately one jolt per second. The diameter of the spread mortar is measured in two directions at right angles to each other using callipers and both results are reported (20).

\subsection{Measurement of setting time}

Initial and final setting times were determined using Vicat method described in (21). The time elapsed since the mixing water was added to the binder to when the needle penetration is $4 \mathrm{~mm}$ from the base of the mould defines the initial setting time of the mortar. The time when there is less than $0.5 \mathrm{~mm}$ penetration of the needle into the mortar defines the final setting time.

\subsection{Measurement of compressive strength}

Compressive strength testing was carried out on CL90 and PC mortars prepared using SCMs as partially replacement materials to the binder. Six samples of each mortar were tested using a compressive testing machine. Measurements were carried out at a constant stroke rate of $5 \mu \mathrm{ms}^{-1}$.

\subsection{Microstructural Analysis}

Microstructural analysis was carried out using a scanning electron microscope (SEM, LEO 1430VP, Germany). Surface charging of the samples was reduced by the application of a thin layer of gold metal - platinum. Microstructural analysis was carried out on CL90 mortars at $91^{\text {st }}$ and PC mortars at $28^{\text {th }}$ days following mixing. The microstructural changes when the binder is partially replaced with SCMs in hydrated lime and cement mortars are investigated.

\section{RESULTS AND DISCUSSIONS}

\subsection{Transfer Sorptivity}

Figure 1 shows that the presence of $50 \% \mathrm{FA}$ and $70 \%$ GGBS in CL90 mortar resulted in a dramatic increase in transfer sorptivity which is quantitatively equivalent to the transfer sorptivity of PC mortar. Previous research has shown that desorptivity and hence transfer sorptivity increase as the particle size of the binder is increased (2). The CL90, FA and GGBS used in this study have particle size ranges of $0.5-30,0.5-120$ and $3-100 \mu \mathrm{m}$, respectively (Table 1). Particle size distribution of FA and GGBS are also shown in Figure 3. In this study, the fine CL90 binder has been partially replaced with FA and GGBS, the particle size of which are greater than that of CL90. Strong water retaining ability of CL90 mortars is destroyed when FA and GGBS are used as partial replacement materials. The coarser partial replacement levels of GGBS and FA resulted in a more porous and hence coarser pore system of CL90 mortar which allowed an easier water passage from the freshly mixed mortars when in contact with a dry masonry substrate. This means in other words that when CL90 is partially replaced with higer particle size of FA and GGBS, it becomes progessively more water releasing and hence results in a higher transfer sorptivity characteristics.

Figure 2 shows that the presence of $50 \% \mathrm{SF}$ in PC mortar resulted in a dramatic decrease in transfer sorptivity which is quantitatively equivalent to the transfer sorptivity of CL90 mortar. Transfer sorptivity results of Figure 1 and 2 are summarised in Table 3. The PC and SF used in this study have particle size ranges of $0.2-120$ and $0.03-0.3 \mu \mathrm{m}$ respectively (Table 1 ). In this case, the coarser binder (PC) is being partially replaced with a finer binder (SF). Based on the small particle size of SF, therefore higher specific surface area, PC mortars with SF additions would be expected to have a higher water retaining ability. The PC with SF binder has a smaller overall particle size and therefore a higher specific surface area than the PC alone. One of the consequences of the incorporation of fine SF particles is the "filler effect" which is the ability of SF particles to fill the voids within the mortar matrix (22). This leads to a less porous, less permeable mortar and a finer pore system. The decrease in porosity and a finer pore system therefore enable PC mortar 


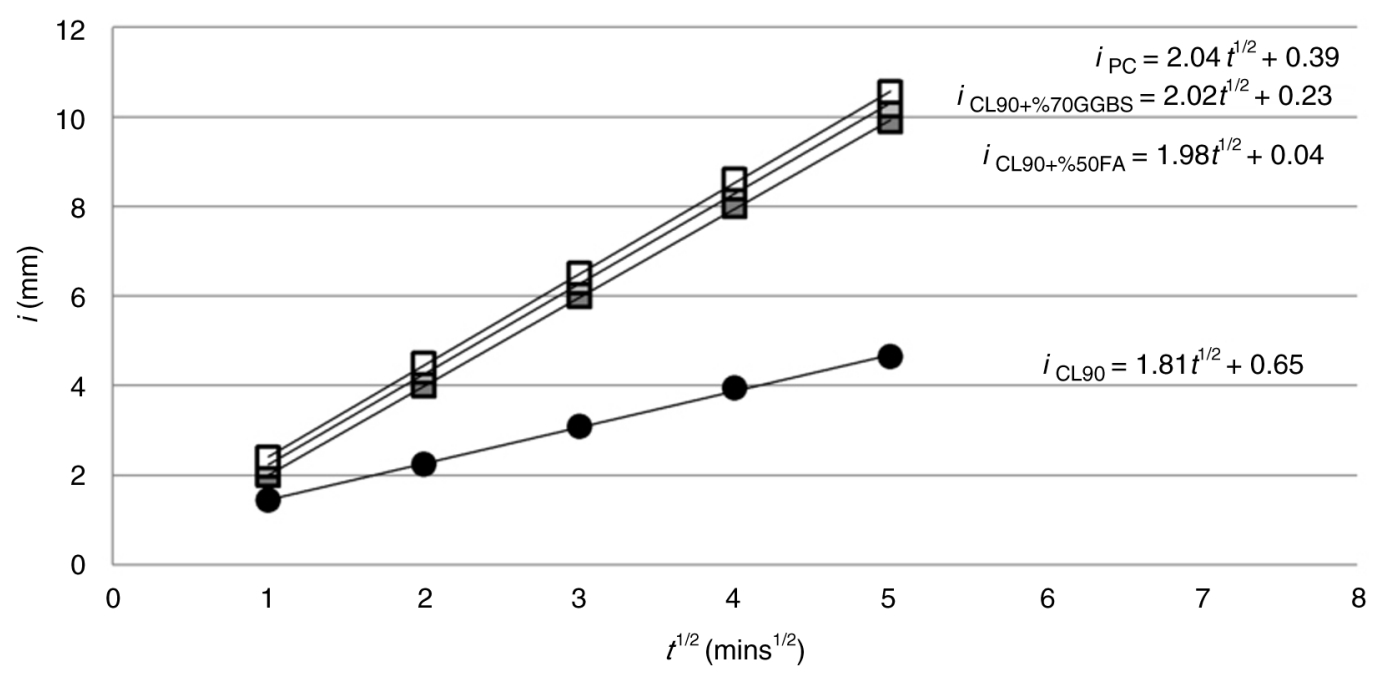

FIgURE 1. Cumulative absorbed volume of water per unit area $i$ versus $t^{1 / 2}$ for $\bullet$, CL90 mortar; $₫$, CL90 mortar with 50\% FA; $\sqsubset$, CL90 mortar with 70\% GGBS; $\square$, PC mortar.

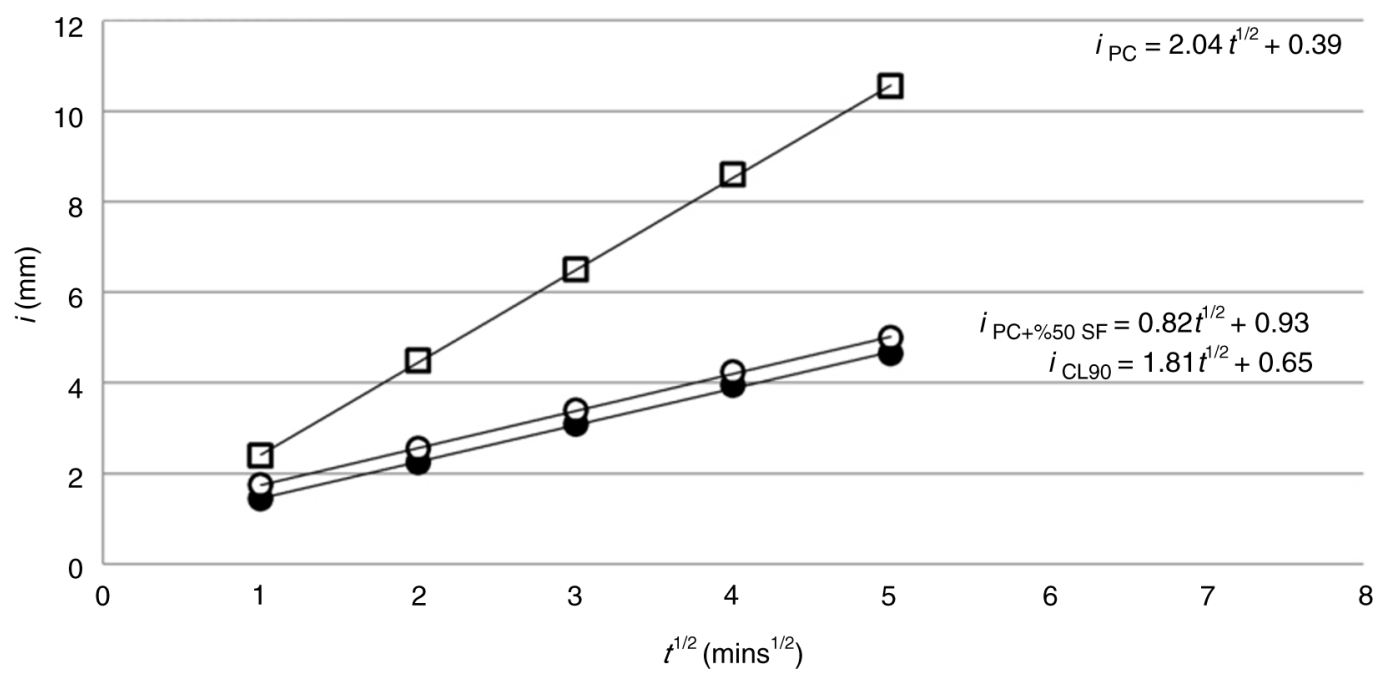

Figure 2. Cumulative absorbed volume of water per unit area $i$ versus $t^{1 / 2}$ for $\bullet$ CL90mortar ;O, PC mortar with \%50 SF; 口, PC mortar.

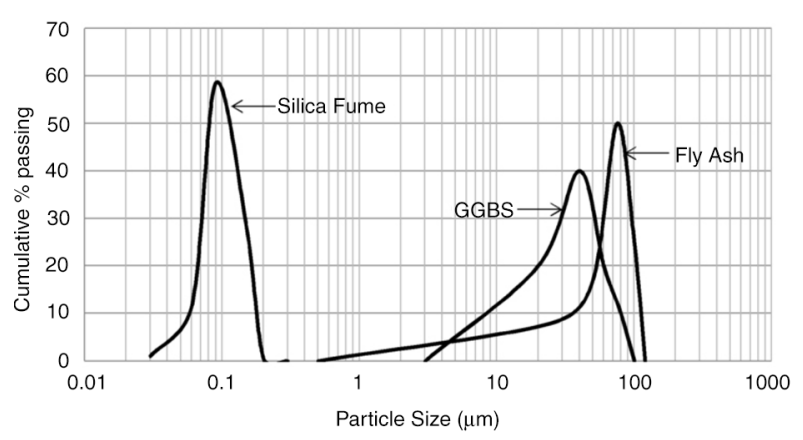

FIGURE 3. Particle size distribution of silica fume, fly ash and GGBS (manufacturer's data). to be more water retaining and hence results in a decrease in transfer sorptivity.

\subsection{Time to dewater}

The measurement of volume fraction of water contents of the mix before and after dewatering is crucial for the calculation of $\alpha$ (Equation [3]). Knowing that the thickness of the mortar bed, $L$, is $20 \mathrm{~mm}$, the time taken to dewater freshly mixed mortars when in contact with and absorbent substrates can also be calculated according to Equation [2]. Experimentally measured values of $\theta_{\mathrm{i}}$ and $\theta_{\mathrm{c}}$ and therefore calculated values of $\alpha$ 
TABLE 3. Transfer sorptivity values of freshly mixed CL90, CL90 with $\% 50$ FA, CL90 with \%70 GGBS and PC mortars

\begin{tabular}{lclc}
\hline Binder & $\begin{array}{c}\text { Transfer Sorptivity, } \\
A\left(\mathbf{m m} / \mathbf{m i n}^{1 / 2}\right)\end{array}$ & \multicolumn{1}{c}{ Binder } & $\begin{array}{c}\text { Transfer Sorptivity, } \\
A\left(\mathbf{m m} / \mathbf{m i n}^{\mathbf{1 / 2}}\right)\end{array}$ \\
\hline CL90 & 0.81 & PC & 2.04 \\
CL90+50\% FA & 1.98 & PC+50\% SF & 0.82 \\
CL90+70\% GGBS & 2.02 & CL90 & 0.81 \\
PC & 2.04 & & \\
\hline
\end{tabular}

and $t_{\mathrm{dw}}$ for CL90, CL90 with \%50 FA, CL90 with $\% 70$ GGBS, PC and PC with \%50 SF mortars are summarised in Table 4.

The results summarised in Table 4 show that measured initial volume fraction water content of the wet mix, $\theta_{\mathrm{i}}$, is increasing with the replacement levels of FA and GGBS in CL90 mortars. We have shown previously that transfer sorptivity of CL90 mortars is increased when $\% 50$ FA and $\% 70$ GGBS are used as replacement to the binder (Table 3). This means in other words that CL90 mortars are becoming more water releasing with the replacement levels of FA and GGBS and hence resulting in a greater decrease in the volume fraction water content of the dewatered mix. The parameters $\alpha$ and $t_{\mathrm{dw}}$ are calculated based on the Equation [3] and Equation [2] respectively. The presence of FA and GGBS resulted in an increase in both $\alpha$ and $A$ in CL90 mortars. The results summarised in Table 4 show that $t_{\mathrm{dw}}$ is decreased when FA and GGBS are used as replacement material to the binder in CL90 mortars.

The results summarised in Table 4 also show that measured initial volume fraction water content of the wet mix, $\theta_{\mathrm{i}}$, is decreasing when $\mathrm{SF}$ is used as a replacement material in cement mortars. As discussed previously, the replacement levels of SF resulted in a decrease in transfer sorptivity (Table 3). This also means that cement mortars are becoming more water retaining with the replacement levels of SF and therefore resulting in an increase in the volume fraction water content of the dewatered mix. The presence of SF resulted in a decrease in both $\alpha$ and $A$ in cement mortars. The results summarised in Table 4 also show that $t_{\mathrm{dw}}$ is increasing when SF is used as replacement material

TABLE 4. Data defining the properties of the mortars before and after dewatering, calculated values of $\alpha$ and $t_{\mathrm{dw}}$

\begin{tabular}{lcccc}
\hline Binder & $\theta_{\mathrm{i}}$ & $\theta_{\mathrm{c}}$ & $\alpha$ & $\boldsymbol{t}_{\mathrm{dw}}(\min )$ \\
\hline CL90 & 0.326 & 0.174 & 0.184 & 20.7 \\
CL90+50\% FA & 0.479 & 0.169 & 0.373 & 14.2 \\
CL90+70\% GGBS & 0.482 & 0.168 & 0.377 & 14.0 \\
PC & 0.483 & 0.166 & 0.380 & 13.9 \\
PC+50\% SF & 0.324 & 0.172 & 0.184 & 20.2 \\
\hline
\end{tabular}

to the binder in cement mortars. Although both parameters influence the calculation of $t_{\mathrm{dw}}$, it can be concluded that $A$ rather than $\alpha$ is the defining parameter in these cases.

It must also be noted that increasing replacement levels of GGBS and FA resulted in a systematic increase in transfer sorptivity and consequently a systematic decrease in time to dewater of CL90 mortars while increasing replacement levels of SF resulted in a systematic decrease in transfer sorptivity and therefore a systematic increase in time to dewater of cement mortars.

\subsection{Consistency}

The effects of supplementary cementitious materials on the consistency of hydrated lime and cement mortars are investigated herein. Consistency of CL90 mortars when GGBS and FA are used as replacement materials are summarised in Table 5. In this case, fine CL90 binder is partially replaced with FA and GGBS, the particle size of which are greater than that of CL90. Increasing replacement levels of both GGBS and FA resulted in an overall increase in the particle size of the binders that reduced the water demand for the mix and hence resulted in a systematic increase in consistency of hydrated lime mortars. The results summarised in Table 5 show that the consistency of CL90 mortars are quantitatively equal to the consistency of PC mortars, when $\% 70$ GGBS and \%50 FA are used as replacement materials. This furhter suggests that consistency of CL90 mortars can be modified when SCMs are used as partially replacement materials to the binder.

Consistency of cement mortars when SF is used as a replacement material is summarised in Table 6. In this case, the coarser binder (PC) is being partially replaced with a finer binder (SF). Increasing replacement levels of SF resulted in a systematic decrease in the consistency of cement mortars due to the increase in water demand for the fresh mix. In fact, the consistency of cement mortars when $\% 50 \mathrm{SF}$ is used is quantitatively equal to the consistency of CL90 mortars. Results presented in Table 6 also suggest that consistency of cement mortars can be modified when SF is used a partial replacement material to cement. 
TABLE 5. Consistency of CL90 mortars using GGBS and FA as replacement material

\begin{tabular}{lclc}
\hline Binder & Consistency (mm) & \multicolumn{1}{c}{ Binder } & Consistency (mm) \\
\hline CL90 control sample & 163 & CL90 control sample & 163 \\
CL90+\% 10 GGBS & 165 & CL90+\% 10 FA & 168 \\
CL90+\% 20 GGBS & 170 & CL90+\% 20 FA & 177 \\
CL90+\% 30 GGBS & 180 & CL90+\% 30 FA & 185 \\
CL90+\% 40 GGBS & 182 & CL90+\% 40 FA & 190 \\
CL90+\% 50 GGBS & 186 & CL90+\% 50 FA & 198 \\
CL90+\% 60 GGBS & 190 & & \\
CL90+\% 70 GGBS & 198 & & \\
\hline
\end{tabular}

TABLE 6. Consistency of CEM mortars using SF as a replacement material

\begin{tabular}{lc}
\hline Binder & Consistency $(\mathbf{m m})$ \\
\hline CEM (control sample) & 198 \\
$\mathrm{CEM}+\%$ 10 SF & 195 \\
$\mathrm{CEM}+\%$ 20 SF & 178 \\
$\mathrm{CEM}+\%$ 30 SF & 168 \\
$\mathrm{CEM}+\%$ 40 SF & 165 \\
$\mathrm{CEM}+\%$ 50 SF & 163 \\
\hline
\end{tabular}

\subsection{Setting time}

The time taken to dewater freshly mixed mortars when using supplementary cementitious materials are measured previously and therefore, CL90 mortar, CL90 mortar with \%50 FA and CL90 mortar with $\% 70$ GGBS are placed on top of a clay facing brick and dewatered for approximately 20.7, 14.2 and 14.0 minutes respectively. Cement mortars and cement mortars with $\% 50 \mathrm{SF}$ are also placed on top of a clay facing brick and dewatered for approximately 13.9 and 20.2 minutes respectively. The dewatering procedure was crucial to perform prior to the setting time measurements

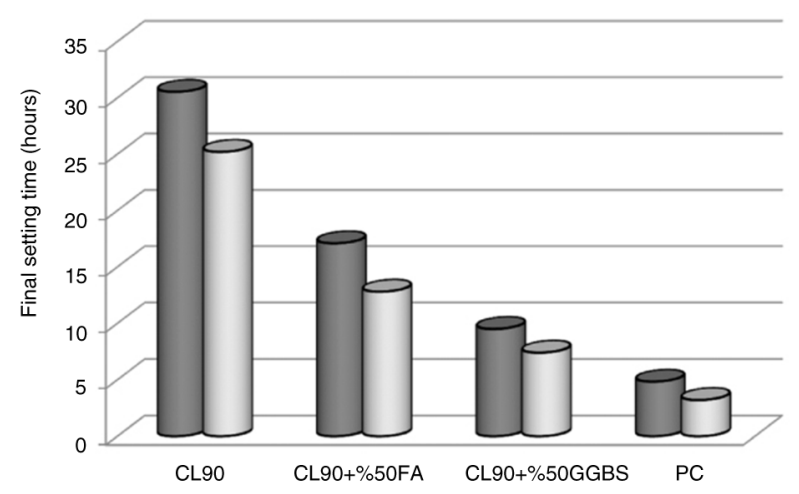

FIGURE 4. Setting time of CL90 and PC mortars. $\bullet$, Non-dewatered mortars; $\bullet$, dewatered mortars. as these mortars would be placed in brick/block substrates and dewatered to certain degrees in construction practice. Final setting time of dewatered and non-dewatered CL90 mortars, CL90 mortars with \%50 FA and CL90 mortars with \%70 GGBS are shown in Figure 4. The final setting time of dewatered and non-dewatered cement mortars are plotted in Figure 4 for comparison. It can be seen in Figure 4 that the presence of both replacement levels of $\% 50$ FA and \%70 GGBS resulted in a significant decrease in the final setting time of CL90 mortars. When dewatered and non-dewatered mortars are compared, it can be concluded that dewatering alone also resulted in a greater decrease in the final setting time of all type of mortars measured. This is an important finding as the long setting time is one of the main barriers to the use of hydrated lime mortars in construction practice. Significant reduction in the setting time when FA and GGBS are used as partial replacement materials in hydrated lime mortars can allow easier and faster use of such materials in construction practice.

Final setting time of dewatered and non-dewatered cement mortars and cement mortars with \%50 SF are shown in Figure 5. The final setting time of dewatered and non-dewatered CL90 mortars are plotted in Figure 5 for comparison. The results shown

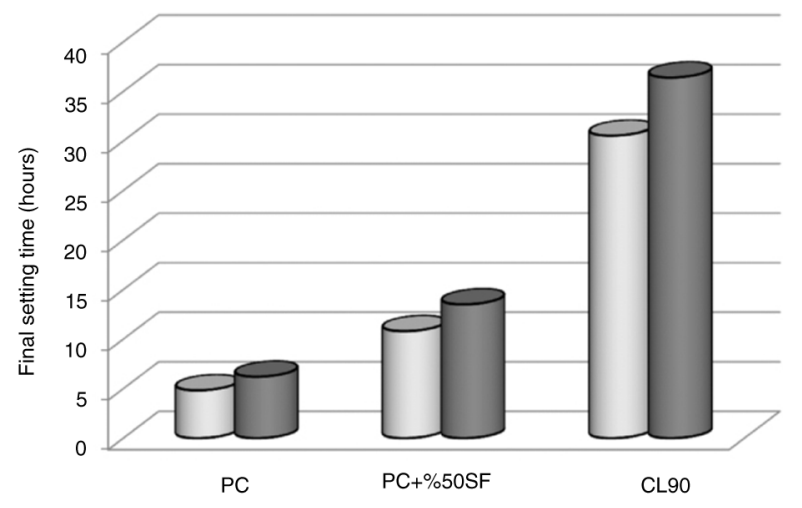

Figure 5. Setting time of CL90 and PC mortars. $\bullet$ Non-dewatered mortars; $\bullet$, dewatered mortars. 
in Figure 5 indicate that the setting time of cement mortars can be increased when SF is used as a partial replacement material to cement. The setting time of CL90 mortar is provided for comparison in Figure 5. Similar to results shown in Figure 4, dewatering of all types of mortars also resulted in a reduction in the final setting time. This indicates that the setting time of cement mortars can be modified when longer setting time of cement mortar is required for practice.

\subsection{Compressive Strength}

Similar dewatering procedure is also followed here prior to moulding samples for compressive strength test as described above. In construction practice, these mortars are applied to the brick/ block substrates in their freshly-mixed state and are dewatered to certain degrees and therefore dewatering procedure should not be underestimated as it significantly affects the set and hardened state properties of these mortars.

Compressive strength results of CL90 mortars, CL90 mortars with 10, 20, 30, 40, 50, 60 and 70\% GGBS are measured at 28th, 56th and 91st days and are shown in Figure 6. Results presented in Figure 6 show that the compressive strength of CL90 mortars is increasing with the increasing replacement levels of GGBS and that higher increase in compressive strength is observed at 91st days. Dramatic increase in compressive strength caused by the replacement levels of GGBS in CL90 mortars is also supported with the microstructural analysis taken on the sample following cured for 91 days and is shown in Figure 9(c). It was reported in (23) that GGBS initially reacted with calcium hydroxide and resulted in a breakdown of the glassy structure of the slag. Microstructural analysis of CL90 mortar with $70 \%$ GGBS shown in Figure 9(c) indicates that the formation of needle-like crystals, C-S-H crystals, account for the increased strength of these mortars are quite evident when particularly compared to the microstructural image of CL90 mortar shown in Figure 9(a) where there are no C-S-H

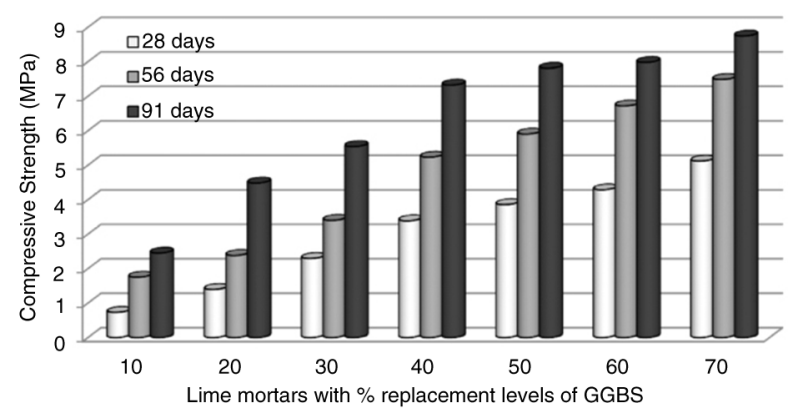

Figure 6. Compressive strength of CL90 mortars when GGBS is used as a replacement material. crystals apparent. It must also be noted that the increase in the replacement levels of GGBS resulted in an enhanced dewatering characteristics of CL90 mortars. Results presented in this paper are also similar to those reported by (3) and strongly suggest that dewatering resulted in a reduced water:binder ratio as a consequence of the increase in transfer sorptivity and it has further contributed for the increased compressive strength of these mortars.

Compressive strength results of CL90 mortars, CL90 mortars with 10, 20, 30, 40 and 50\% FA are measured at $28^{\text {th }}, 56^{\text {th }}$ and $91^{\text {st }}$ days and are shown in Figure 7. There is a systematic increase in the compressive strength of CL90 mortars when FA is used up to $\% 40$. Increasing replacement level of FA beyond $\% 40$ does not enhance the compressive strength of CL90 mortars further. It must also be noted that the increase observed in CL90 mortars when FA is used as a replacement material is much less than that observed with the replacement levels of GGBS. Higher increase in compressive strength is also observed at $91^{\text {st }}$ days. The microstructural analysis of CL90 mortars with \%50 replacement levels of FA, following cured for 91 days, is shown in Figure 9(b). Figure 9(b) suggests that dewatering is the main phase responsible for the increased compressive strength and not the formation of C-S-H crystals as they are not much visible in the micrograph.

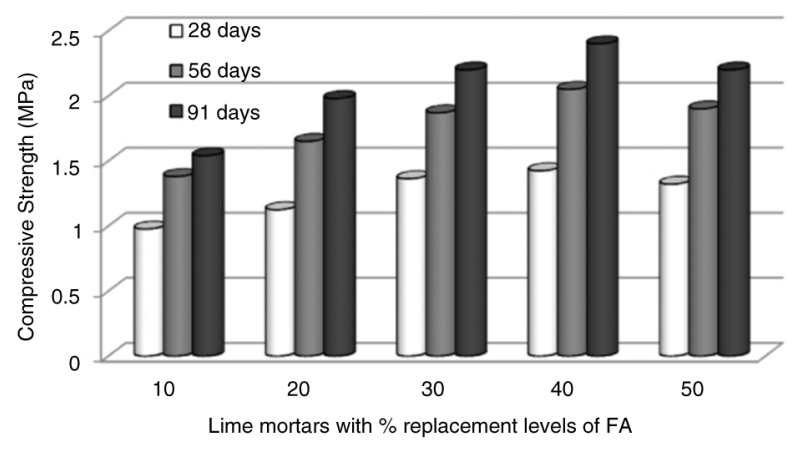

FIGURE 7. Compressive strength of CL90 mortars when FA is used as a replacement material.

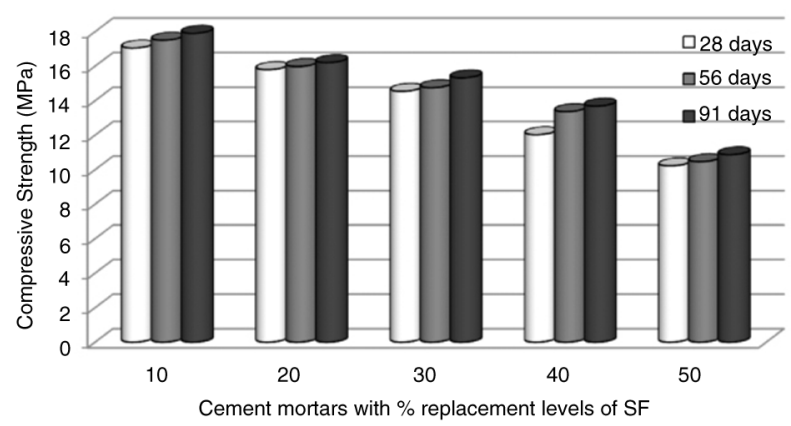

FIGURE 8. Compressive strength of PC mortars when $\mathrm{SF}$ is used as a replacement material. 
(a)

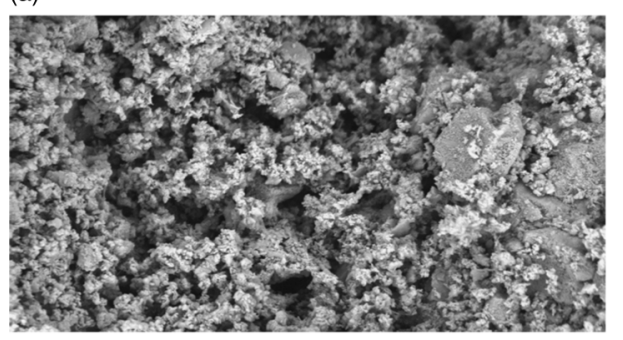

(c)

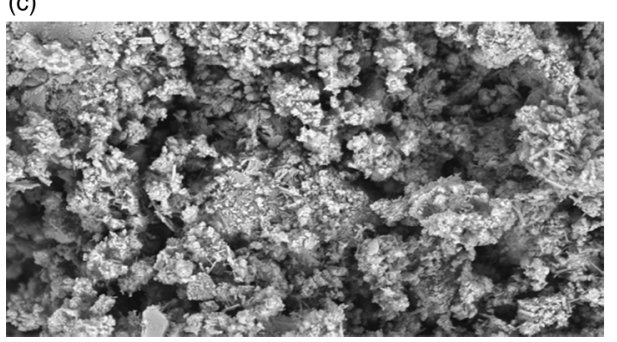

(b)

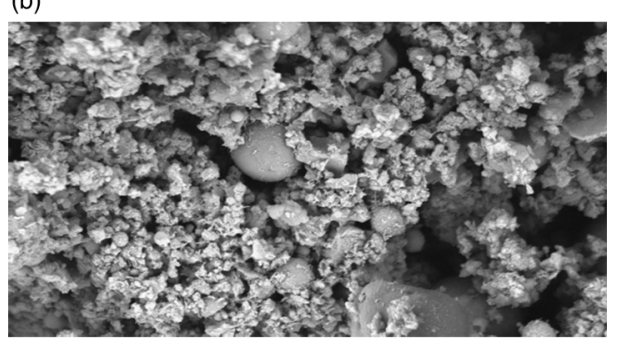

(d)

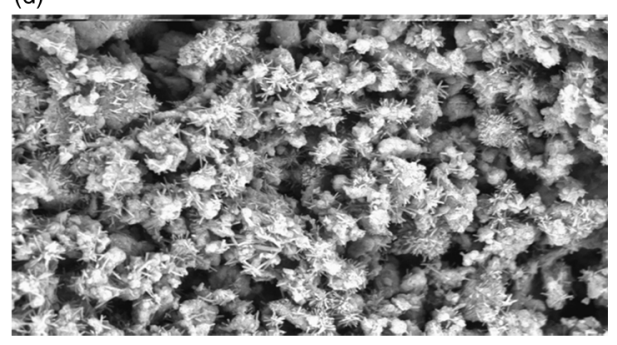

(e)

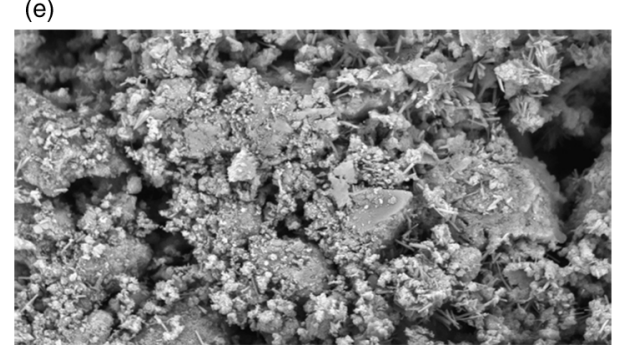

FIGURE 9. Scanning electron micrographs of mortars (a), CL90 mortars; (b) CL90 mortars with \%50 FA; (c), CL90 mortars with 70\% GGBS; (d), PC mortars; (e), PC mortars with $\% 50 \mathrm{SF}$.

Compressive strength results of cement mortars, cement mortars with $10,20,30,40$ and $50 \%$ SF are also measured at $28^{\text {th }}, 56^{\text {th }}$ and $91^{\text {st }}$ days and are shown in Figure 8. The results show that the increasing replacement levels of SF in cement mortars resulted in a systematic decrease in the compressive strength. The microstructural analysis of cement and cement mortars with 50\% replacement levels of SF following cured for 28 days are shown in Figure 9(d) and (e) respectively. The formation of C-S-H crystals shown for the cement mortars in Figure 9(d) are reduced enormously when \%50 $\mathrm{SF}$ is used as a replacement levels in cement mortars shown in Figure 9(e). Significant reduction of C-S-H crystals on the micrograph of cement mortars with $\% 50$ replacement levels of SF essentially was responsible for the decrease in compressive strength.

\section{CONCLUSIONS}

Development of the experimental procedure for transfer sorptivity and time taken to dewater freshly mixed hydrated lime mortars have allowed the investigation of the influence of supplementary cementitious materials on the water transport kinetics of hydrated lime and cement mortars. Experimental measurements of the parameters such as initial and final volume fraction of water contents were extremely challenging considering that those measurements had to be done at the freshly mixed state of hydrated lime and cement mortars.

Experimental measurements of initial and final volme fraction water contents allowed the calculation of $\alpha$, complex parameter that involves the volume fraction of water and solids content that are in the mix before and after dewatering. Time to dewatering of hydrated lime and cement mortars when SCMs are used as replacement materials therefore are calculated using Equation [2]. Results have shown that time to dewater of hydrated lime and cement mortars can be modified when SCMs are used as replacement materials. The use of SCMs also allowed the modification of transfer sorptivity characteristics of these mortars which means in other words the water retaining ability of such mortars can be influenced simply using SCMs.

We have shown in this paper that the low consistency and long setting time of hydrated lime mortars can be improved when SCMs are used as replacement materials. More water is usually added to the mix to increase the consistency of hydrated lime mortars in practice however this affects the set and hardened 
states properties of the resulting mix and causes a considerable reduction in compressive strength.

Low compressive strength of CL90 mortars are increased dramatically especially when GGBS is used as a replacement material and the results are supported with the microstructural analysis where it was clear that not only dewatering but also the formation of the C-S-H crystals played a significant role in the increase in compressive strength. The slight increase in compressive strength of CL90 mortars when FA is used as a replacement material is also supported with the microstructural analysis and that dewatering primarily found to be responsible for the increased in compressive strength in this case. The results also showed that the high compressive strength of cement mortars could also be modified when SF is used as a replacement material. In this case, cement is being replaced with less hydraulic binder, SF, and this has led to the reduced C-S-H crystals on the hardened state of cement mortars and further resulted in a decrease in compressive strength.

We must emphasise that modification of the water transport characteristics of hydrated lime and cement mortars is vital for mortar/substrate optimisation in masonry construction. We have shown in this paper that the modification of both water transport characteristics and mechanical properties of these mortars is possible and has a significant beneficial effect on properties in the set and hardened state. It is well known in the construction industry that mortars made with hydrated lime have lower workability and strength than the equivalent cement mortar. This reason among others has meant that lime mortars until fairly recently had fallen out of use. The results presented here may facilitate the reintroduction of hydrated lime materials in construction practice.

\section{ACKNOWLEDGEMENTS}

Authors would like to acknowledge Entegre Ltd., Akcim Mining and Cement Indusrty Ltd, Cimkul Ltd and Metal Tube Manufacturing Industry Ltd for materials supply necessary for the experimental work of this study and would like to acknowledge Hülya Özyurt, laboratory technician, for assisting associated experiments.

\section{REFERENCES}

1. Carter, M.A.; Green, K.M.; Wilson, M.A.; Hoff, W.D. (2003) Measurement of the water retentivity of cement mortars. Adv. Cem. Res. 15 [4], 155-159. http://dx.doi.org/10.1680/ adcr.2003.15.4.155.

2. Ince, C.; Carter, M.A.; Wilson, M.A.; El-Turki, A.; Ball, R.J.; Allen, G.C.; Collier, N.C. (2010) Analysis of the abstraction of water from freshly mixed jointing mortars in masonry construction. Mater. Struct. 43 [7], 985-992. http://dx.doi.org/10.1617/s11527-009-9560-5.

3. El-Turki, A.; Ball, R.J.; Carter, M.A.; Wilson, M.A.; Ince, C.; Allen, G.C. (2010) Effect of dewatering on the strength of lime and cement mortars. J. Amer. Ceram.
Soc. 93 [7], 2074-2081. http://dx.doi.org/10.1111/j.15512916.2010.03667.x.

4. Ince, C.; Carter, M.A.; Wilson, M.A. (2013) The water retaining characteristics of lime mortars. Mater. Struct. Published Online 30 November 2013. http://dx.doi.org/ 10.1617/s11527-013-0224-0.

5. Andrejkovičováa, S.; Velosab, A.L.; Ferrazb, E.; Rochaa, F. (2014) Influence of clay minerals addition on mechanical properties of air lime-metakaolin mortars. Constr. Build. Mater. 65, 132-139. http://dx.doi.org/10.1016/j. conbuildmat.2014.04.118.

6. Gameiro, A.; Santos Silva, A.; Faria, P.; Grilo, J.; Branco, T.; Veiga, R.; Velosa, A. (2014) Physical and chemical assessment of lime-metakaolin mortars: Influence of binder: aggregate ratio. Cem. Concr. Compos. 45, 264-271. http://dx.doi.org/ 10.1016/j.cemconcomp.2013.06.010.

7. Nežerka, V.; Sližková, Z.; Tesárek, P.; Plachý, T.; Frankeová, D.; Petráňová, V. (2014) Comprehensive study on mechanical properties of lime-based pastes with additions of metakaolin and brick dust. Cem. Concr. Res. 64, 17-29. http://dx.doi.org/10.1016/j.cemconres.2014.06.006.

8. Mertens, G.; Snellings, R.; Van Balen, K.; Bicer-Simsir, B.; Verlooy, P.; Elsen, J. (2009) Pozzolanic reactions of common natural zeolites with lime and parameters affecting their reactivity. Cem. Concr. Res. 39 [3], 233-240. http:// dx.doi.org/10.1016/j.cemconres.2008.11.008.

9. Matias, G.; Faria, P.; Torres, I. (2014) Lime mortars with ceramic wastes: characterization of components and their influence on the mechanical behaviour. Constr. Build. Mater. 73, 523-534. http://dx.doi.org/10.1016/j. conbuildmat.2014.09.108.

10. Bulut U. (2010) Use of Perlite as a Pozzolanic Addition in Lime Mortars. Gazi Uni. J. Sci. 23 [3], 305-313.

11. Ozturk, Y. (2011) The use of supplementary cementing materials in the manipulation of mix water transport in mortar-masonry systems. MPhil Thesis, The University of Manchester, UK.

12. Collier, N.C.; Wilson, M.A.; Carter, M.A.; Hoff, W.D.; Hall, C.; Ball, R.J.; El-Turki, A.; Allen, G.C. (2007) Theoretical development and validation of a sharp front model of the dewatering of a slurry by an absorbent substrate. J. Phys. D 40 [13], 4049-4054. http://dx.doi.org/ 10.1088/0022-3727/40/13/022.

13. Hall, C.; Hoff, W.D. (2002) Water transport in brick, stone and concrete. Taylor and Francis, London, UK.

14. BSI (2010) EN 459-1:2010. Building Lime. Definitions, specifications and conformity criteria. BSI, London, UK.

15. BSI (2005) EN 450-1:2005 Fly ash for concrete. Definition, specifications and conformity criteria. BSI, London, UK.

16. BSI (2006) EN 15167-1:2006 Ground granulated blast furnace slag for use in concrete, mortar and grout. Definitions, specifications and conformity criteria. BSI, London, UK.

17. BSI (2009) EN 13263-1:2009 Silica fume for concrete. Definitions, requirements and conformity criteria. BSI, London, UK.

18. BSI (2002) EN 13139:2002 Aggregates for mortar. BSI, London, UK.

19. Ince, C.; Carter, M.A.; Wilson, M.A.; Collier, N.C.; El-Turki, A.; Ball, R.J.; Allen, G.C. (2011) Factors Affecting the Water Retaining Characteristics of Lime and Cement Mortars in the Freshly-Mixed State. Mater. Struct. 44 [2], 509-516. http://dx.doi.org/10.1617/s11527-010-9645-1.

20. BSI (1999) EN 1015-3:1999. 'Methods of test for mortar for masonry. Determination of consistence of fresh mortar (by flow table)'. BSI, London, UK.

21. BSI (2005) EN 196-3:2005+A1:2008. 'Methods of testing cement. Determination of setting times and soundness'. BSI, London, UK.

22. Domone, P.; Illston, J. (2010) Construction materials: their nature and behaviour, 4th edn. Taylor \& Francis, London, UK.

23. Richardson, D.N. (2006) Organizational Results Research Report - Strength and Durability of a 70\% Ground Granulated Blast Furnace Slag Concrete Mix. Missouri Transportation Institute and Missouri Department of Transportation, USA. 